\title{
Evaluating Conservation Effectiveness of Nature Reserves Established for Surrogate Species: Case of a Giant Panda Nature Reserve in Qinling Mountains, China
}

\author{
XU Weihua ${ }^{1}$, Andrés VIÑA ${ }^{2}$, QI Zengxiang ${ }^{3}$, OUYANG Zhiyun $^{1}$, LIU Jianguo ${ }^{2}$, LIU Wei ${ }^{2}$, WAN Hui ${ }^{4}$ \\ (1. State Key Laboratory of Regional and Urban Ecology, Research Center for Eco-Environmental Sciences, Chinese Academy of Sci- \\ ences, Beijing 100085, China; 2. Center for Systems Integration and Sustainability, Department of Fisheries and Wildlife, Michigan \\ State University, East Lansing, MI 48823, USA; 3. College of Design and Art, University of South China, Hengyang 421001, China; 4. \\ World Wide Fund for Nature (WWF) Xi'an Programme Office, Xi'an 710075, China)
}

\begin{abstract}
Many nature reserves are established to protect the habitat needs of particular endangered species of interest but their effectiveness for protecting other species is questionable. In this study, this effectiveness was evaluated in a nature reserve network located in the Qinling Mountains, Shaanxi Province, China. The network of reserves was established mainly for the conservation of the giant panda, a species considered as a surrogate for the conservation of many other endangered species in the region. The habitat suitability of nine protected species, including the giant panda, was modeled by using Maximum Entropy (MAXENT) and their spatial congruence was analyzed. Habitat suitability of these species was also overlapped with nature reserve boundaries and their management zones (i.e., core, buffer and experimental zones). Results show that in general the habitat of the giant panda constitutes a reasonable surrogate of the habitat of other protected species, and giant panda reserves protect a relatively high proportion of the habitat of other protected species. Therefore, giant panda habitat conservation also allows the conservation of the habitat of other protected species in the region. However, a large area of suitable habitat was excluded from the nature reserve network. In addition, four species exhibited a low proportion of highly suitable habitat inside the core zones of nature reserves. It suggests that a high proportion of suitable habitat of protected species not targeted for conservation is located in the experimental and buffer zones, thus, is being affected by human activities. To increase their conservation effectiveness, nature reserves and their management zones need to be re-examined in order to include suitable habitat of more endangered species. The procedures described in this study can be easily implemented for the conservation of many endangered species not only in China but in many other parts of the world.
\end{abstract}

Keywords: giant panda; habitat suitability; Maximum Entropy (MAXENT); nature reserve network; surrogate species

Citation: Xu Weihua, Viña Andrés, Qi Zengxiang, Ouyang Zhiyun, Liu Jianguo, Liu Wei, Wan Hui, 2014. Evaluating conservation effectiveness of nature reserves established for surrogate species: Case of a giant panda nature reserve in Qinling Mountains, China. Chinese Geographical Science, 24(1): 60-70. doi: 10.1007/s11769-014-0656-7

\section{Introduction}

The establishment of nature reserves is one of the main ways for protecting species diversity (Margules and Pressey, 2000, Rodrigues and Andelman, 2004). Usually the location and areal extent of nature reserves have been selected based on empirical information as well as expert opinion on the distribution of surrogate species (Lambeck, 1997; Caro and O'Doherty, 1999). Surrogate species have mostly been selected based on their narrow distribution (e.g., endemic), significant ecological roles (e.g., key-stone), low occurrence (e.g., rare, endangered)

Received date: 2013-04-09; accepted date: 2013-07-23

Foundation item: Under the auspices of National Natural Science Foundation of China (No. 40901289), Major State Basic Research

Development Program of China (No. 2009CB421104), U.S. National Science Foundation

Corresponding author: XU Weihua.E-mail: xuweihua@rcees.ac.cn

(C) Science Press, Northeast Institute of Geography and Agroecology, CAS and Springer-Verlag Berlin Heidelberg 2014 
and charisma (e.g., flagship), among others (Lambeck, 1997; Caro and O'Doherty, 1999; Favreau et al., 2006), with the aim of protecting many other sympatric species. However, the effectiveness of surrogate species varies among species and geographic regions, therefore the use of surrogate species for nature reserve establishment has been questioned (Caro and O'Doherty, 1999; Andelman and Fagan, 2000; Favreau et al., 2006).

The effectiveness of surrogate species for the conservation of other species has been evaluated at different spatial scales (Liu et al., 1995; Caro and O'Doherty, 1999; Andelman and Willig, 2003; Rodrigues et al., 2004) and among different taxa (Grantham et al., 2010), using field survey data or other inventory data (Favreau et al., 2006). Correlation analysis has been the main approach to assess habitat preference (Wei et al., 1999; Shen et al., 2009), or spatial relationships between the surrogate and other species (Warman et al., 2004; Williams et al., 2006). These results offered some insights on the suitability of surrogate species, but few guidelines on nature reserve establishment or other conservation management actions have been provided (Grantham et al., 2010). In contrast, habitat modeling, which provides spatial information on species distribution and spatial congruence among species, has not been widely used for assessing surrogate species.

In China, a total of 2640 nature reserves had been established by the end of 2011 , covering around $14.9 \%$ of the land surface of China (Ministry of Environmental Protection, the People's Republic of China, 2012). Many endangered and charismatic species, including the giant panda (Ailuropoda melanoleuca), the tiger (Panthera tigris) and the Asian elephant (Elephas maximus), have been used as surrogates for the establishment of these nature reserves, however, their effectiveness for the conservation of other species has seldom been evaluated (Li et al., 2002). The conservation effectiveness of nature reserves also depends on management actions that enforce conservation policies and reduce human impacts (Liu et al., 2001). According to the law on management of nature reserves in China (Decree No. 167 of the State Council, the People's Republic of China, 1994), nature reserves should be divided into three main management zones: core, experimental and buffer zones (Hull et al. 2011). Core zones are characterized by well-preserved natural ecosystems that constitute suitable habitats for rare and/or endangered species. These areas can not be used in any way for human activities such as fuelwood collection and timber harvesting (Bearer et al., 2008), tourism (He et al., 2008), agriculture (Liu, 2010), and house construction (Linderman et al., 2005). Experimental zones are the areas that also constitute suitable habitat but have been subjected to human influence. Buffer zones are established to mitigate the impacts on the core zones of human activities occurring in the experimental zones (The State Concil of the People's Republic of China, 1994).

Nevertheless, few specific and operable criteria have been devised for establishing the boundaries of these management zones, with the result that they have been established by simply encircling the areas where the surrogate species have been frequently observed ( $\mathrm{Li}$ et al., 1999), or established following elevational contour lines for the reserves established previously. Therefore, areas that constitute habitat for other endangered species might be excluded from the core zones and placed in the experimental and buffer zones, with potentially negative effects on species conservation, and thus on the overall conservation effectiveness of nature reserves.

The location and extent of suitable habitat areas of endangered species can be interpolated with the location and extent of nature reserves, in order to evaluate their conservation effectiveness, as well as to suggest additional conservation actions (Cabeza et al., 2004). In this study, we evaluated the effectiveness of a nature reserve network, specifically designed for protecting the habitat of the endangered and charismatic giant panda, in conserving the habitat of other endangered species. The main goal is to identify and map the location and extent of the areas that constitute suitable habitat for other endangered wildlife species, in addition to the surrogate one (i.e., giant panda), in order to evaluate the effectiveness of the location of the nature reserve system and its management zones (i.e., core, buffer and experimental zones) for protecting the habitat of different endangered wildlife species. Specific objectives are to: 1) assess the habitat suitability of nine protected wildlife species; 2) evaluate the effectiveness of using the giant panda as a surrogate species; and 3) evaluate the effectiveness of the nature reserve network established for the giant panda in protecting other protected species.

\section{Materials and Methods}

\subsection{Study area}

This study was conducted in the Qinling Mountains, 
Shaannxi Province, China $\left(32^{\circ} 40^{\prime}-34^{\circ} 20^{\prime} \mathrm{N}, 106^{\circ} 40^{\prime}-\right.$ $\left.109^{\circ} 40^{\prime} \mathrm{E}\right)$ (Fig. 1). Four major vegetation types are distributed among an elevational range between $367 \mathrm{~m}$ and $3767 \mathrm{~m}$ : evergreen broad-leaf forest (below $1300 \mathrm{~m}$ ), mixed evergreen and deciduous broad-leaf forest (1300 $2000 \mathrm{~m})$, coniferous forest (2000-3200 m), scrubs and meadow (above $3200 \mathrm{~m})(\mathrm{Hu}, 2001)$. The total area comprises ca. $23586 \mathrm{~km}^{2}, 14 \%$ of which is included inside 14 nature reserves established before 2006 mainly to protect the habitat of the endangered giant pandas. In addition to the giant panda, other protected wildlife species are found in the study area, including such charismatic species as the golden snob- nosed monkey (Rhinopithecus roxellanae) and the takin (Budorcas taxicolor) (Hu, 2001).

\subsection{Species selection}

To test the effectiveness of a nature reserve system designed for the protection of the giant panda (i.e., surrogate species) in the conservation of other endangered species (i.e., target species), we selected target species by using four criteria: 1) being included as a protected species in the list of China protection class list, 2) covering different mammal and bird species with diverse niche requirements, 3) covering a wide range of life histories and forest habitat requirements, and 4) high data accessibility. According to the 3rd national survey report of giant pandas in China (State Forestry Administration, the People's Republic of China, 2006), 42 species in six orders (e.g., falconiformes, galliformes, stri- giformes, primates, canivora, and artiodactyla) in China's protection class list are found in the Qinling Mountains region. Eight protected species in four orders, in addition to giant pandas, were selected (Table 1). These species cover a wide range of life histories and all forest habitat requirements at elevation between $500 \mathrm{~m}$ and $3400 \mathrm{~m}$. For instance, among these species, four species are distributed in mixed coniferous/broad-leaf forests or coniferous forests in high mountains areas (from $2000 \mathrm{~m}$ to $3400 \mathrm{~m}$ or higher), two species in broad-leaf forests and mixed broad-leaf/coniferous forests in middle elevation, and the others in middle to lower elevation (from about $500 \mathrm{~m}$ to $2600 \mathrm{~m}$ ). In terms of food preferences, two species feed on young tree leaves or grasses, three prefer tree leaves, grasses, fruits and seeds, and the remaining three species have an omnivorous diet (Table 1).

\subsection{Habitat modeling}

\subsubsection{Model selection}

Several models based on geographic information systems have been developed and used to evaluate the habitat distribution of many species (Guisan and Thuiller, 2005). Due to the fact that false absence data can decrease the reliability of predictive models, together with the difficulty for obtaining accurate absence data, we chose to use a presence-only model that has been shown to have high predictive accuracy, the Maximum Entropy (MAXENT) model, a general purpose machine-learning method for making predictions from incomplete infor-

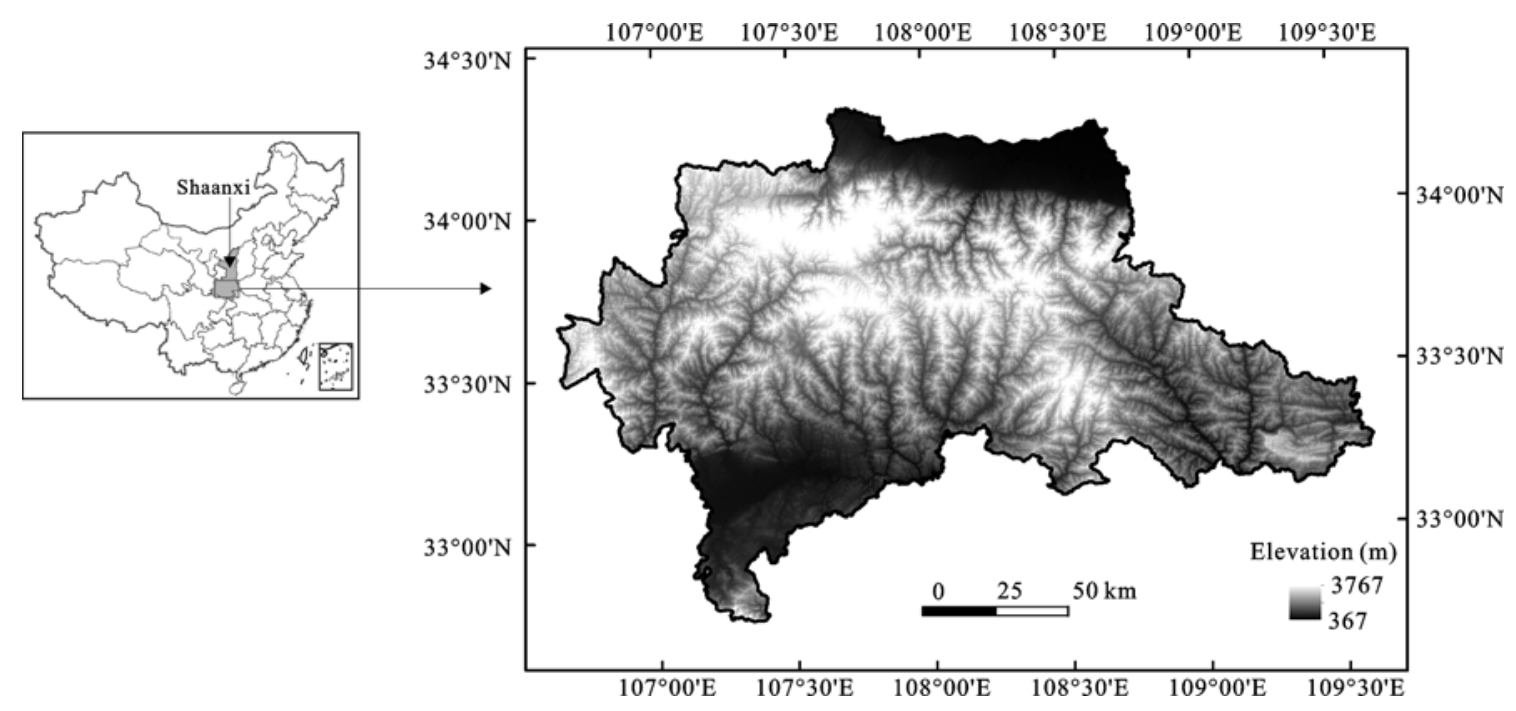

Fig. 1 Location of study area in Qinling Mountains, Shaanxi Province, China. Overlapped with a digital elevation model (DEM) obtained from National Geomatics Center of China (NGCC). Shades of gray indicate elevation in meter 
Table 1 List of protected species included in this study

\begin{tabular}{|c|c|c|c|c|c|c|}
\hline $\begin{array}{l}\text { Species } \\
\text { number }\end{array}$ & Name & Latin name & $\mathrm{CPC}$ & IUCN & Distribution information & $\begin{array}{c}\text { No. of occurrence } \\
\text { points }\end{array}$ \\
\hline 1 & Black bear & $\begin{array}{c}\text { Ursus } \\
\text { thibetanus }\end{array}$ & II & VU & $\begin{array}{l}\text { This species has six sub-species, distributed in forests especially } \\
\text { broad-leaf forests or mixed coniferous/broad-leaf forests throughout } \\
\text { China. In Sichuan Province, distribution elevation is above } 1000 \mathrm{~m} \text {. } \\
\text { Its main food includes grasses, young tree leaves, nuts, fruits, as well } \\
\text { as fish, frogs and birds (Ma et al., 1998, Wang, 1998a) }\end{array}$ & 115 \\
\hline 2 & Blood pheasan & $\begin{array}{l}\text { Ithaginis } \\
\text { cruentus }\end{array}$ & II & LC & $\begin{array}{l}\text { Mainly distributed in coniferous forests or mixed coniferous/ } \\
\text { broad-leaf forests in Tibet Autonomous Region, Yunnan, Sichuan, } \\
\text { Shaanxi and Gansu provinces, within the range between } 2200 \mathrm{~m} \\
\text { and } 3200 \mathrm{~m} \text { in the Qinling Mountains. Its main food includes seeds, } \\
\text { fruits, tree buds and young leaves (Wang, 1998b) }\end{array}$ & 70 \\
\hline 3 & $\begin{array}{l}\text { Golden snob- } \\
\text { nosed monkey }\end{array}$ & $\begin{array}{l}\text { Pygathrix } \\
\text { roxellanae }\end{array}$ & I & EN & $\begin{array}{l}\text { Mainly distributed between } 1500 \mathrm{~m} \text { and } 3300 \mathrm{~m} \text { in deciduous and } \\
\text { coniferous forests in Sichuan, Shaanxi, Hubei and Gansu provinces, } \\
\text { China. Its main food includes leaves, flowers, fruits and seeds } \\
\text { (Wang, 1998a) }\end{array}$ & 178 \\
\hline 4 & Golden pheasant & $\begin{array}{l}\text { Chrysolophus } \\
\text { pictus }\end{array}$ & II & LC & $\begin{array}{l}\text { Mainly distributed in shrubs, evergreen broad-leaf, or mixed broad- } \\
\text { leaf/coniferous forests in Gansu, Sichuan, Shaanxi, Guizhou, Hunan } \\
\text { and Hubei provinces, ranging from } 500 \mathrm{~m} \text { to } 2500 \mathrm{~m} \text {. Its main food } \\
\text { includes leaves, flowers, fruits and seeds of some shrubs, and insects } \\
\text { (Wang, 1998b; Liang et al., 2003) }\end{array}$ & 169 \\
\hline 5 & Chinese goral & $\begin{array}{l}\text { Naemorhedus } \\
\text { griseus }\end{array}$ & II & VU & $\begin{array}{l}\text { This species is distributed in forests especially broad-leaf forests or } \\
\text { mixed coniferous/broad-leaf forests throughout China. In Shaanxi } \\
\text { Province, its distribution elevation is above } 1000 \mathrm{~m} \text {. Its main food } \\
\text { includes grasses, young tree leaves, and fruits (Wang, 1998a) }\end{array}$ & 231 \\
\hline 6 & Koklass pheasant & $\begin{array}{c}\text { Pucrasia } \\
\text { macrolopha }\end{array}$ & II & LC & $\begin{array}{l}\text { Mainly distributed in shrubs, evergreen broad-leaf, or mixed } \\
\text { broad-leaf/coniferous forests, ranging from } 1100 \mathrm{~m} \text { to } 2400 \mathrm{~m} \text { in the } \\
\text { Qinling Mountains. Its main food includes leaves, flowers, fruits and } \\
\text { seeds of some shrubs, and insects (Wang, 1998b) }\end{array}$ & 89 \\
\hline 7 & Mainland serow & $\begin{array}{c}\text { Capricornis } \\
\text { milneedwardsii }\end{array}$ & II & NT & $\begin{array}{l}\text { Mostly found in coniferous and mixed broad-leaf/coniferous forests } \\
\text { (mostly above } 1000 \mathrm{~m} \text { ) of the southern China. Its main food includes } \\
\text { grasses, young branches and leaves of trees, as well as mushrooms } \\
\text { (Wang, 1998a; Zhou, 2005) }\end{array}$ & 191 \\
\hline 8 & Takin & $\begin{array}{l}\text { Budorcas } \\
\text { taxicolor }\end{array}$ & I & VU & $\begin{array}{l}\text { Mainly distributed in coniferous and mixed broad-leaf/coniferous } \\
\text { forests (mostly between } 2000 \mathrm{~m} \text { and } 3400 \mathrm{~m} \text { ) in Tibet, the Qinling } \\
\text { Mountains of Shaanxi Province, and the Minshan and Qionglai } \\
\text { mountains in Gansu and Sichuan provinces. Its main food sources } \\
\text { are young tree branches and leaves, as well as grasses (Wang, 1998a; } \\
\text { Zeng et al., 2003) }\end{array}$ & 273 \\
\hline 9 & Giant panda & $\begin{array}{l}\text { Ailuropoda } \\
\text { melanoleuca }\end{array}$ & I & EN & $\begin{array}{l}\text { Mainly distributed in deciduous and coniferous forests in six moun- } \\
\text { tain ranges in Sichuan, Shaanxi and Gansu provinces. In Minshan } \\
\text { Mountain, it is mainly distributed between } 1200 \mathrm{~m} \text { and } 3800 \mathrm{~m} \text {. } \\
\text { More than } 95 \% \text { of its food is bamboo (Schaller } \text { et al., 1985) }\end{array}$ & 268 \\
\hline
\end{tabular}

Notes: CPC, China protection class. I, national first-class protection; II, national second-class protection. Referring to Wang et al. (1998a; 1998b) for more information about China protection class system and endangered species. IUCN, conservation status. EN, endangered; VU, vulnerable; LC, least concern; NT, nearly threatened. Referring to IUCN Red List Categories and Criteria Version 3.1 (http:/intranet.iucn.org/webfiles/doc/SSC/RedList/ redlistcatsenglish.pdf)

mation (Phillips, 2006). Using a set of environmental predictor variables combined with a set of species occurrence data as input, MAXENT determines the probability of an area to be habitat for a species of interest. This is done by finding a probability distribution of maximum uniformity (or maximum entropy) subject to the constraint that the expected value of each environmental predictor variable under this estimated distribution matches the empirical average of the set of species occurrence data (Phillips, 2006). The output of MAXENT is a probability map interpreted as a habitat suitability index (HSI), whose values range from 0 (unsuitable) to
1 (perfectly suitable). The MAXENT has been shown to be robust in modeling presence-only data, outperforming many other traditional habitat distribution models including GARP, DOMAIN and BIOCLIM (Elith et al., 2006; 2011; Cecilia et al., 2007). Detailed information about MAXENT is given by Phillips (2006) as well as Phillips and Dudik (2008).

\subsubsection{Species occurrence data}

The spatial locations of the evidence of the occurrence of the nine protected species studied were obtained in field surveys conducted between 2006 and 2008. These field surveys were conducted year-round (i.e., in all 
seasons) so that the differences in habitat preferences observed throughout the year were also included in the habitat modeling. These field surveys were carried out by the nature reserve system personnel, along 480 different monitoring routes inside the nature reserves as well as in some surrounding areas outside them. During these field surveys, the geographic locations of evidence of the occurrence of protected species (e.g., feces, tracks) were recorded by using global positioning system receivers whenever these evidences were found. A total of 1584 locations were obtained, ranging from 70 points for the blood pheasant to 273 points for the takin (Table 1).

\subsubsection{Environmental predictor variables}

Two types of environmental predictor variables were used for modeling the habitat suitability of the nine protected species: 1) elevation data in lattice format obtained from a digital elevation model (DEM) developed by the National Geomatics Center of China (NGCC) at a spatial resolution of $90 \mathrm{~m} \times 90 \mathrm{~m}$. 2) 2004-2007 time series of the wide dynamic range vegetation index (WDRVI) obtained from an image time series (184 weekly composite images; $250 \mathrm{~m} \times 250 \mathrm{~m} /$ pixel) acquired by the moderate resolution imaging spectroradiometer (MODIS) on board the Terra Satellite. Similar to the widely used normalized difference vegetation index (NDVI), the WDRVI is a remotely sensed index of vegetation greenness, but it exhibits sensitivity to changes in vegetation when the NDVI saturates (Viña and Gitelson, 2005). This vegetation index was successfully used in giant panda habitat modeling not only in a single reserve (i.e., the Wolong Nature Reserve in Sichuan Province) (Tuanmu et al., 2010) but across the entire giant panda geographic range (Viña et al., 2008; 2010). To reduce the dimensionality of the WDRVI image time series, we used the first 20 principal components obtained from applying a principal component analysis to the 184 WDRVI images. Principal components derived from WDRVI image time series were proven useful for panda habitat modeling across the entire geographic range of the species (Viña et al., 2010). All these spatially explicit predictor variables were coregistered in the UTM WGS84 coordinate system, and re-sampled to a common grid of $250 \mathrm{~m} \times 250 \mathrm{~m} /$ pixel.

\subsubsection{Model validation}

As the output of MAXENT is not discrete but a continuous range from 0 to 1 , a threshold-independent validation procedure was preferred. Thus we used the area under the receiver operating characteristic curve (AUC) (Hanley and McNeil, 1982) for evaluating the prediction accuracy of the output HSI maps. The AUC has been used extensively as a measure of a model's overall performance in discriminating between sites where a species is present, versus those where it is absent. The AUC validation procedure was implemented in the software MAXENT 3.3.3k, by using 10000 randomly selected background pixels that were used as pseudo-absence. For the presence data, we divided the occurrence data of all nine species studied into training and validation through a randomization procedure in which $70 \%$ of the data were used for training and the remaining $30 \%$ were used for validation. The AUC has the values ranging between 0 and 1 , where a score of 1 indicates perfect discrimination, a score of 0.5 implies a discrimination that is no better than random, and lower than 0.5 implying worse than random (Phillips, 2006).

\subsection{Evaluation of giant panda as a surrogate species}

To use the habitat distribution of one species as a surrogate for the habitat of another, a high spatial congruence in the distribution of their suitable habitats must occur. Therefore, we evaluated the habitat of the giant panda as a surrogate for the habitat of the other species studied following two procedures. 1) We calculated Spearman rank-ordered correlation coefficients between the giant panda's HSI values and those of the other eight species studied. The HSI values were extracted by using ArcGIS 10.0 and correlation coefficients were calculated by using SPSS. 2) We established the degree of spatial overlap between the habitat of the giant panda and the habitat of each of the other species by calculating the ratio of the overlapped area to the total habitat area of the nonsurrogate species. In addition, in order to evaluate the conservation effectiveness of giant panda nature reserves, we overlapped the habitat map of each of the nine species with the boundaries of the 14 reserves in the study area, and calculated the proportions of habitat areas inside nature reserves (relative to the total habitat area in the study area) and inside the core zones of nature reserves (relative to the total habitat area inside reserves).

For calculating the proportions of habitat inside nature reserves, the continuous HSI were separated into habitat and non-habitat areas for the nine protected species, by identifying an optimal HSI cumulative threshold. The threshold was selected for each species by the cal- 
culation of maximum Kappa by using pixels with species occurrence, and the same amount of pixels obtained randomly across the study area (Viña et al., 2010). The highly suitable habitat was obtained by using an HSI cumulative threshold of 0.3 which was used to calculate the proportion of highly suitable habitat of each of the nine species evaluated inside core zones of nature reserves.

\section{Results}

\subsection{Modeling outputs}

The AUC values were above 0.9 for all species studied, suggesting a high prediction success rate of the MAXENT models (Fig. 2). The results of output HSI maps show that most suitable habitat for all species is distributed in the middle and western parts of the study area. Among them, some species such as the Chinese goral, koklass pheasant, takin, golden pheasant and black bear, exhibit large habitat areas, while mainland serow, blood pheasant, giant panda, and golden snobnosed monkey exhibit comparatively lower habitat areas.

\subsection{Spatial congruence of habitat}

Spearman rank-correlation coefficients between the HSI values of the giant panda and those of the other species studied ranged between 0.50 and $0.84(p<0.01)$, with takin, mainland serow and golden snob-nosed monkey showing the highest values (above 0.75), which indicated a high spatial congruence between their habitats and that of the giant panda (Table 2).

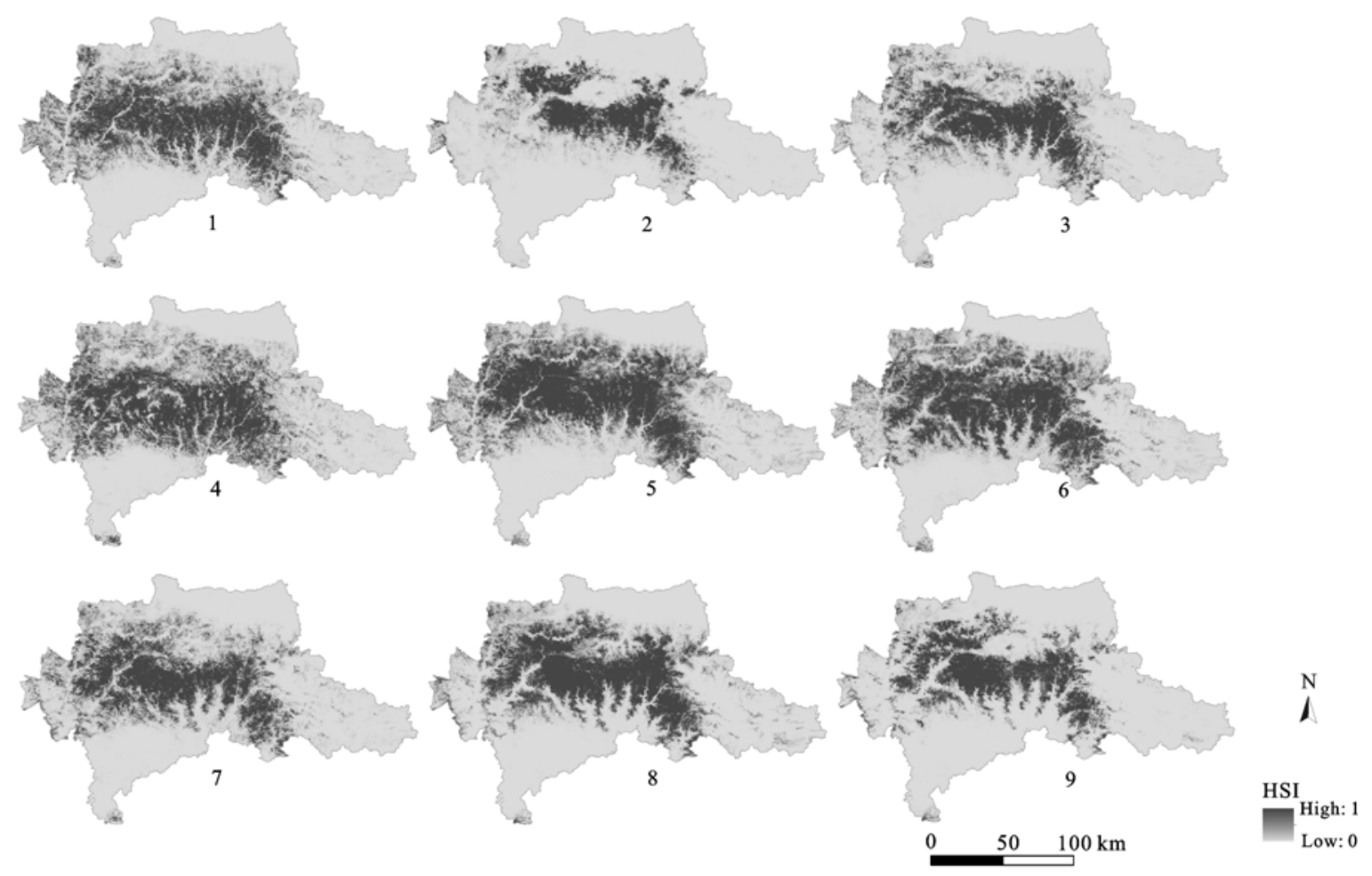

Fig. 2 Habitat suitability index (HSI) maps obtained for nine protected species by using MAXENT. 1, black bear, AUC $=0.975 ; 2$, blood pheasant, $\mathrm{AUC}=0.985 ; 3$, golden snob-nosed monkey, $\mathrm{AUC}=0.974 ; 4$, golden pheasant, $\mathrm{AUC}=0.963 ; 5$, Chinese goral, $\mathrm{AUC}=$ $0.948 ; 6$, koklass pheasant, $\mathrm{AUC}=0.976 ; 7$, mainland serow, $\mathrm{AUC}=0.973 ; 8$, takin, $\mathrm{AUC}=0.960 ; 9$, giant panda, $\mathrm{AUC}=0.974$

Table 2 Spearman rank-correlation coefficients and habitat coverage percentage between giant panda and eight target species

\begin{tabular}{crrrrrrrrr}
\hline & 1 & 2 & 3 & 4 & 5 & 6 & 7 & 8 \\
\hline Correlation coefficient & 0.68 & 0.67 & 0.75 & 0.50 & 0.73 & 0.67 & 0.77 & 0.84 \\
Coverage (\%) & 59.06 & 93.04 & 78.71 & 54.41 & 52.92 & 57.76 & 70.01 & 70.48 \\
\hline
\end{tabular}

Notes: 1, black bear; 2, blood pheasant; 3, golden snob-nosed monkey; 4, golden pheasant; 5, Chinese goral; 6, koklass pheasant; 7, mainland serow; 8, takin. Spearman rank-correlation coefficients are the ones between the HSI values of the giant panda and the other eight protected species. Habitat coverage percentage for each of the eight species is the habitat area covered by giant panda habitat to its total habitat area 
The degree of habitat overlap between the giant panda and the other eight protected species was evaluated after identifying the optimal per-species HSI cumulative threshold. The giant panda exhibited the highest habitat overlap ratio (above 70\%) with blood pheasant, takin, mainland serow and golden snob-nosed monkey, confirming the results obtained through the Spearman-rank correlation coefficients described above (Table 2). In addition, the giant panda habitat also covered $93.04 \%$ of the blood pheasant habitat but this was mainly due to its small area rather than to a high correlation coefficient. The overlap ratios with the other four species were below $60 \%$.

\subsection{Nature reserve representativeness}

Giant panda nature reserves cover large amounts of the habitat areas of the nine protected species studied, as they contain 2-3 times higher proportions of the habitat of these species than the proportion (14\%) of the study area they comprise (Fig. 3a, Fig. 4). However, the proportions for four species including black bear, golden pheasant, Chinese goral, and koklass pheasant were much lower than that of the giant panda. It suggested that nature reserves included relatively high proportions of suitable habitat areas of these species in general, but still had the potential for improvement.

A different figure was obtained when evaluating the

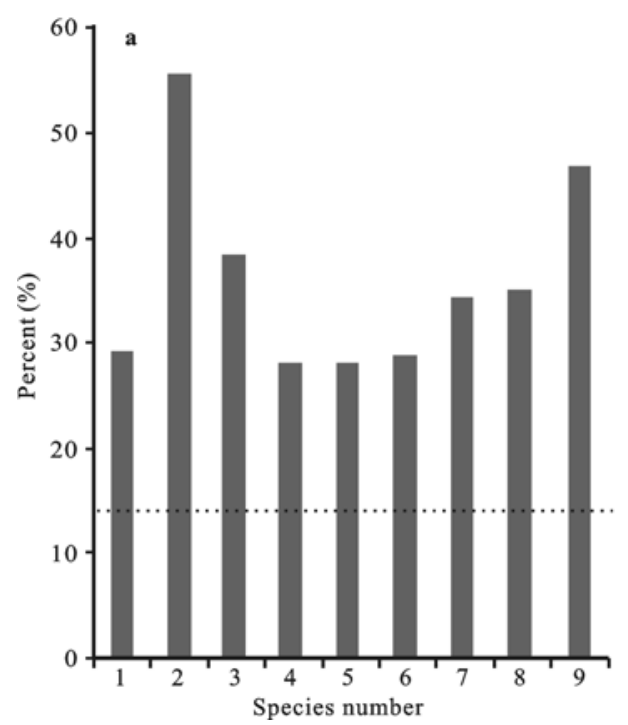

proportion of high suitable habitat areas inside core zones, as it showed high variability among the species studied. Only for the surrogate species (the giant panda) and the species exhibiting high spatial overlap with the surrogate (blood pheasant, mainland serow, takin, and golden snob-nosed monkey), the proportion of highly suitable habitat inside core zones was higher than that of the area inside core zones to total nature reserve area, implying that a significant proportion of the highly suitable habitat areas of these species was located inside core zones of nature reserves (Fig. 3b, Fig. 4). In contrast, the other four species exhibited a relatively low proportion (Fig. 3b), especially black bear, golden pheasant and koklass pheasant which exhibit the values below $40 \%$ in the proportion of the core zones to the total nature reserve area. It indicated that the highly suitable habitat for these species was mostly distributed inside the buffer and experimental zones of nature reserves.

\section{Conclusions and Discussion}

According to China's national biodiversity conservation strategy and action plan, optimization of spatial patterns and improvement of management effectiveness will be among the main tasks for nature reserve establishment in the next few decades (Ministry of Environmental Protection, the People's Republic of China, 2011). There-

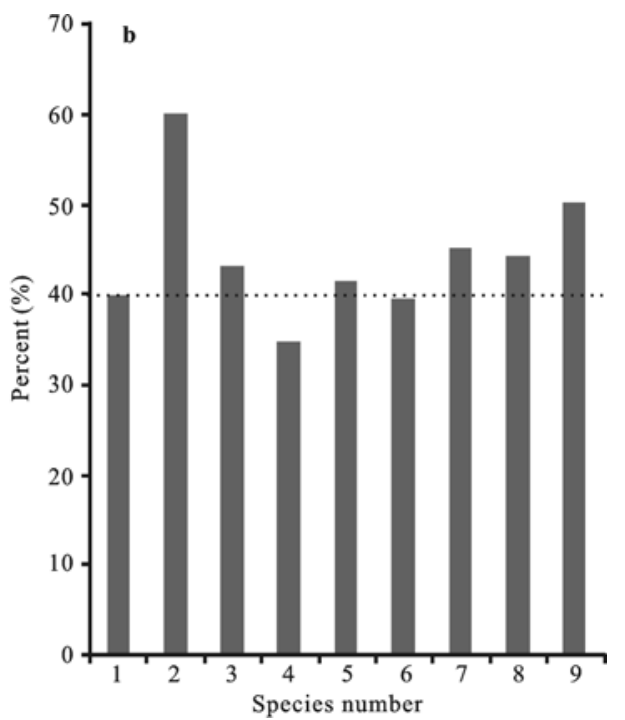

Fig. 3 Conservation effectiveness of giant panda nature reserves for habitat of nine protected species studied. a, area ratio of habitat inside nature reserves to total habitat. Dotted line represents area proportion of study area inside nature reserves. $b$, area ratio of habitat inside core zones to habitat inside nature reserves. Dotted line represents ratio of area inside core zones to total nature reserve area. 1 , black bear; 2, blood pheasant; 3, golden snob-nosed monkey; 4, golden pheasant; 5, Chinese goral; 6, koklass pheasant; 7, mainland serow; 8 , takin; 9 , giant panda 


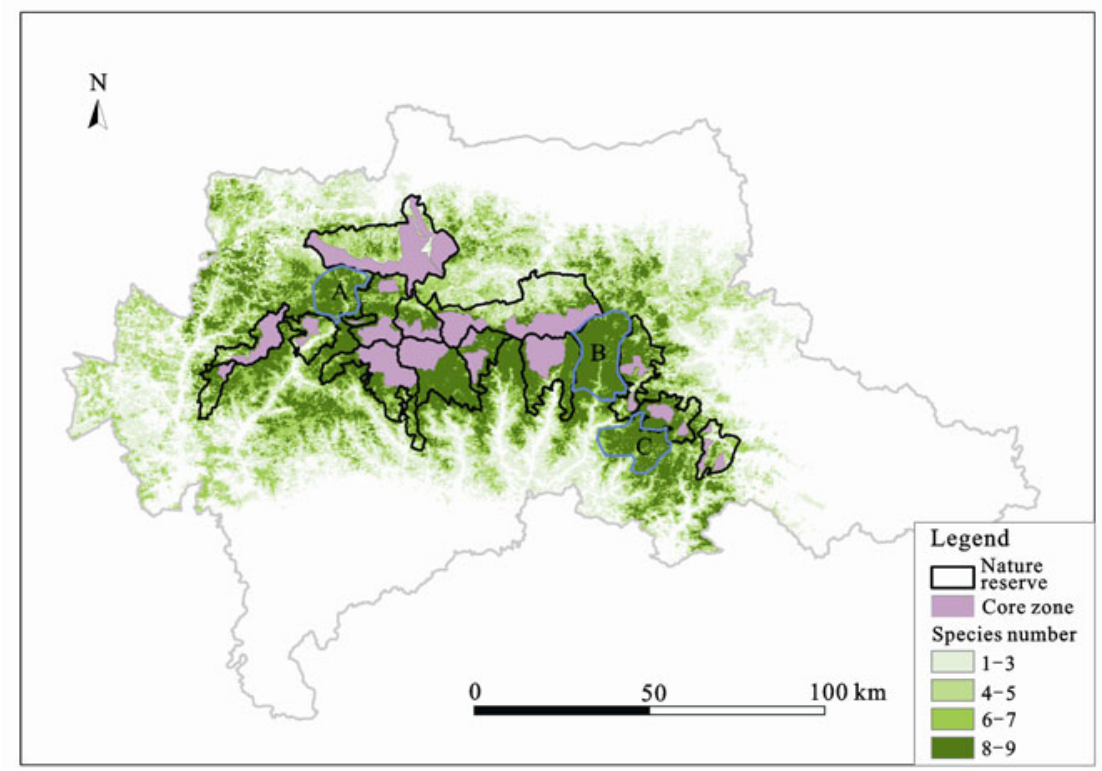

Fig. 4 Current management zones of nature reserves and areas where nature reserves need to be increased. Shades of green indicate accumulated times in each pixel for nine species habitat. A, B and C indicate the areas should be included inside the reserves in the future. 1, black bear; 2, blood pheasant; 3, golden snob-nosed monkey; 4, golden pheasant; 5, Chinese goral; 6, koklass pheasant; 7, mainland serow; 8 , takin; 9 , giant panda

fore, a comprehensive evaluation is needed on the current nature reserves, in order to determine the optimal locations that cover the habitat of numerous species. With literally thousands of species to protect, it is not feasible to analyze the conservation effectiveness for all species. Thus it is necessary to use surrogate species in comprehensive conservation plans for protecting multiple species and habitats within defined geographic areas. While this constitutes a simplification, developing effective conservation management plans without their use would not be practical. This simplification also allows focusing on a finite and manageable set of key elements to determine if conservation goals are being achieved. The challenge is then to select the optimal species to be used as surrogates, i.e., those that emphasize the commonalities in the conservation needs of multiple species, and thus result in more systematic, holistic and effective management practices.

In this study, we evaluated the effectiveness using a charismatic species, the giant panda, as a surrogate species for conservation. At least in the Qinling Mountains region and among the nine protected species evaluated, our results support the current widespread use of the giant panda as a surrogate species for conservation, since its habitat showed a relatively high spatial congruence with that of the other protected species evalu- ated. It could be explained by the fact that being an elevational migrant (Schaller et al., 1985), the habitat of the giant panda is comprised by a wide range of forest types that also constitute habitat for several other wildlife species (Table 1) (Schaller et al., 1985; Ma et al., 1998; Wang, 1998a; 1998b; Liang et al., 2003; Zeng et al., 2003; Zhou, 2005; Xu et al., 2006). Additionally, nature reserves established for the giant panda are also covering a significant proportion of suitable habitat of other protected species, particularly the species that exhibit similar habitat requirements to those of the pandas. However, the proportions of suitable habitat of four species (black bear, golden pheasant, Chinese goral, and koklass pheasant) inside nature reserves were considerably lower than that of the giant panda. In addition, these four species exhibited a low proportion (close to or below the ratio of the core zones to the entire reserves) of highly suitable habitat within the core zones. Since the core zones were designed especially for protecting suitable habitat for the giant panda, only the suitable habitat of species that exhibit similar habitat requirements to those of the giant panda are located in the core zones, while the habitat of other species, although also inside nature reserves, is not located within core zones and are placed instead in the buffer and experimental zones. Therefore, these species are being subjected to higher 
pressure derived from human activities (e.g., tourism, herb collection, grazing and agriculture) allowed in these zones. It suggested that the effectiveness of giant panda nature reserves on protecting the overall biodiversity of the region is reduced. Therefore, the boundaries of nature reserves and different management zones in the study area need to be modified in order to protect suitable habitat of additional protected species and to reduce human influence. For instance, some areas (A, B and $\mathrm{C}$ in Fig. 4) should be included inside the reserves, since these zones contain large areas highly suitable habitat of several different species (e.g., black bear, golden pheasant, Chinese goral, and koklass pheasant). Furthermore, incorporation of these highly suitable habitat areas into the core zones of nature reserves will reduce the effects of human activities, and thus improve the effectiveness of giant panda nature reserves in protecting other protected species.

Most evaluations of the effectiveness of surrogate species were based on expert opinion and correlation analysis (Warman et al., 2004; Williams et al., 2006; Shen et al., 2009). In contrast, the methodology presented here constitutes an objective, cost-effective, fast and practical tool for assisting in nature reserve design and management, particularly in the areas undergoing fast environmental change due to the pervasive influence of human activities, as it is the case of China (Liu and Diamond, 2005). It provides a meaningful criterion for establishing the boundaries of not only nature reserves but also of their management zones (core, experimental and buffer zones), so that suitable habitat of many protected wildlife species is included inside the core zone of nature reserves. An additional advantage is that this approach can be carried out at different scales, from individual nature reserves to entire nature reserve networks, as long as appropriate species occurrence and spatially explicit environmental predictor variables are available.

Approaches similar to the one presented here may be carried out in different locations and at different spatial scales. Such analyses will contribute to the establishment of an optimized and efficient nature reserve network that enhances the biodiversity conservation not only in China but around the world. Nevertheless, the approach has some limitations. First, only eight species in addition to the giant panda were evaluated, constituting ca. $20 \%$ of the total number of protected wildlife species reported in the study area (State Forestry Administration, the People's Republic of China, 2006). Although the species were selected specifically to reduce redundancy in their life histories and habitat requirements, these species are certainly not representative of all taxa. Thus, future studies need to incorporate as many endangered species as possible, to properly assess the effectiveness of current nature reserve networks in protecting their habitats. Second, the approach depends on the accuracy of the habitat model predictions. These will mainly depend on the type of model selected (Guisan and Zimmermann, 2000), and on the environmental predictor variables used, as not all environmental predictor variables are suitable for every species considered. Thus, additional environmental predictors need to be added in order to improve the accuracy of the approach to be used for different species and across different taxa (e.g., invertebrates, plants). Third, results are scale dependent (Favreau et al., 2006), as regional (e.g., mountain regions, provinces, countries) evaluations may produce different results to those performed at smaller scales such as individual nature reserves due to the differences in the geographic distribution of species. In this case, further research needs to be carried out comprising the entire geographic range of the giant panda, to obtain a comprehensive evaluation on the effectiveness of the entire giant panda nature reserve network in protecting other endangered species. Despite these limitations, our approach constitutes a relatively simple but robust and cost-effective procedure for assessing the effectiveness of using particular surrogate species in conservation management.

\section{Acknowledgements}

We thank the Forestry Department of Shaanxi Province for providing species occurrence data.

\section{References}

Andelman S J, Fagan W F, 2000. Umbrellas and flagships: Efficient conservation surrogates or expensive mistakes? Proceedings of the National Academy of Sciences of the United States of America, 97(11): 5954-5959. doi: 10.1073/pnas. 100126797

Andelman S J, Willig M R, 2003. Present patterns and future prospects for biodiversity in the western Hemisphere. Ecology Letters, 6(9), 818-824. doi: 10.1046/j.1461-0248.2003.00503.x Bearer S L, Linderman M, Huang J et al., 2008. Effects of fuel- 
wood collection and timber harvesting on giant panda habitat use. Biological Conservation, 141(2): 385-393. doi: 10.1016/ j.biocon.2007.10.009

Cabeza M, Araújo M B, Wilson R J et al., 2004. Combining probabilities of occurrence with spatial reserve design. Journal of Applied Ecology, 41(2), 252-262. doi: 10.1111/j.0021-8901. 2004.00905.x

Caro T M, O'Doherty G, 1999. On the use of surrogate species in conservation biology. Conservation Biology, 13(4): 805-814. doi: 10.1046/j.1523-1739.1999.98338.x

Cecilia S, Rui F, David D et al., 2007. Modelling bryophyte distribution based on ecological information for extent of occurrence assessment. Biological Conservation, 135(3): 341-351. doi: 10.1016/j.biocon.2006.10.018

Elith J, Graham C H, Anderson R P et al., 2006. Novel methods improve prediction of species' distributions from occurrence data. Ecography, 29(2): 129-151. doi: 10.1111/j.2006.09067590.04596.x

Elith J, Phillips S J, Hastie T et al., 2011. A statistical explanation of MaxEnt for ecologists. Diversity and Distributions, 17(1): 43-57. doi: 10.1111/j.1472-4642.2010.00725.x

Favreau J M, Drew C A, Hess G R et al., 2006. Recommendations for assessing the effectiveness of surrogate species approaches. Biodiversity and Conservation, 15(12): 3949-3969. doi: 10.1007/s10531-005-2631-1

Grantham H S, Pressey R L, Wells J A et al., 2010. Effectiveness of biodiversity surrogates for conservation planning: Different measures of effectiveness generate a kaleidoscope of variation. PLOS ONE, 5(7): e11430. doi: 10.1371/journal.pone.0011430

Guisan A, Thuiller W, 2005. Predicting species distribution: Offering more than simple habitat models. Ecology Letters, 8(9): 993-1009. doi: 10.1111/j.1461-0248.2005.00792.x

Guisan A, Zimmermann N E, 2000. Predictive habitat distribution models in ecology. Ecological Modelling, 135(2-3): 147-186. doi: 10.1016/S0304-3800(00)00354-9

Hanley J A, McNeil B J, 1982. The meaning and use of the area under a Receiver Operating Characteristic (ROC) curve. Radiology, 143(1): 29-36. doi: 10.1.1.139.4820

He G M, Chen X D, Liu W et al., 2008. Distribution of economic benefits from ecotourism. Environmental Management, 42(6): 1017-1025. doi: 10.1007/s00267-008-9214-3

$\mathrm{Hu}$ Jingchu, 2001. Research on the Giant Panda. Shanghai: Shanghai Science \& Technology Education Press, 64-67.

Hull V, Xu W H, Liu W et al., 2011. Evaluating the efficacy of zoning designations for protected area management. Biological Conservation, 144(12): 3028-3037. doi: 10.1016/j.biocon. 2011.09.007

Lambeck R J, 1997. Focal species: A multi-species umbrella for nature conservation. Conservation Biology, 11(4): 849-856. doi: 10.1046/j.1523-1739.1997.96319.x

Li W J, Wang Z J, Ma Z J et al., 1999. Designing the core zone in a biosphere reserve based on suitable habitats: Yancheng Biosphere Reserve and the red crowned crane (Grus japonensis). Biological Conservation, 90(3): 167-173. doi: 10.1016/S00063207(99)00028-2
Li Xiaowen, Zhang Ling, Fang Jinyun, 2002. Indicator, umbrella and flagship species: The concepts and their applications in conservation biology. Biodiversity Science, 10(1): 72-79. (in Chinese)

Liang Wei, Zheng Guangmei, Zhang Zhengwang et al., 2003. Habitat use by golden pheasants (Chrysolophus pictus) based on radio-tracking locations. Acta Zoologica Sinica, 49(2): 179-184. (in Chinese)

Linderman M A, An L, Bearer S et al., 2005. Modeling the spatio-temporal dynamics and interactions of households, landscape, and giant panda habitat. Ecological Modelling, 183(1): 47-65. doi: 10.1016/j.ecolmodel.2004.07.026

Liu J, 2010. China' s road to sustainability. Science, 328(5974): 50. doi: $10.1126 /$ science. 1186234

Liu J, Diamond J, 2005. China's environment in a globalizing world-How China and the rest of the world affect each other. Nature, 435: 1179-1186. doi: 10.1038/4351179a

Liu J, Dunning J B, Pulliam H R, 1995. Potential effects of a forest management plan on Bachman's Sparrows (Aimophila aestivalis): Linking a spatially-explicit model with GIS. Conservation Biology, 9(1): 62-79. doi: 10.1046/j.1523-1739.1995. 09010062.x

Liu J, Linderman M, Ouyang Z et al., 2001. Ecological degradation in protected areas: The case of Wolong Nature Reserve for giant pandas. Science, 292(5514): 98-101. doi: 10.1126/ science. 1058104

Ma Yiqing, Xu Li, Hu Qinchu, 1998. On the resources and conservation of bears in China. Life Science Research, 2(3): 205-211. (in Chinese)

Margules C R, Pressey R L, 2000. Systematic conservation planning. Nature, 405: 243-253. doi: 10.1038/35012251

Ministry of Environmental Protection, the People's Republic of China, 2012. Report on the State of Environment in China 2011. Available at: http://jcs.mep.gov.cn/hjzl/zkgb/2011zkgb/. (in Chinese)

Ministry of Environmental Protection, the People's Republic of China, 2011. China National Biodiversity Conservation Strategy and Action Plan. Beijing: China Environmental Science Press, 1-95. (in Chinese)

Phillips S J, 2006. Maximum entropy modeling of species geographic distributions. Ecological Modelling, 190(3-4): 231259. doi: 10.1016/j.ecolmodel.2005.03.026

Phillips S J, Dudik M, 2008. Modeling of species distributions with Maxent: New extensions and a comprehensive evaluation. Ecography, 31(2): 161-175. doi: 10.1111/j.0906-7590.2008. 5203.x

Rodrigues A S L, Andelman S J, 2004. Effectiveness of the global protected area network in representing species diversity. $\mathrm{Na}$ ture, 428: 640-643. doi: 10.1038/nature02422

Schaller G B, Hu J, Pan W et al., 1985. The Giant Pandas of Wolong. Chicago, Illinois, USA: University of Chicago Press, 33-93.

Shen Dingjian, Zheng Hexun, Wang Yu et al., 2009. Winter habitats of dwarf blue sheep and goal in Batang County, Sichuan. Acta Ecologica Sinica, 29(5): 2320-2330. (in Chinese) 
State Forestry Administration, the People's Republic of China, 2006. The 3rd National Survey Report on Giant Panda in China. Beijing: China Science Press, 292-294. (in Chinese)

The State Concile of the People's Republic of China, 1994. Regulations of the People's Republic of China on Nature Reserve. Available at: http://www.gov.cn/ziliao/flfg/2005-09/27/ content_70636.htm. (in Chinese)

Tuanmu M N, Viña A, Bearer S et al., 2010. Mapping understory vegetation using phenological characteristics derived from remotely sensed data. Remote Sensing of Environment, 114(8): 1833-1844. doi: 10.1016/j.rse.2010.03.008

Viña A, Gitelson A A, 2005. New developments in the remote estimation of the fraction of absorbed photosynthetically active radiation in crops. Geophysical Research Letters, 32: L17403. doi: 10.1029/2005GL023647

Viña A, Tuanmu M-N, Xu W et al., 2010. Range-wide analysis of wildlife habitat: Implications for conservation. Biological Conservation, 143(9): 1960-1969. doi: 10.1016/j.biocon.2010. 04.046

Viña, A, Bearer S, Zhang H et al., 2008. Evaluating multi-temporal MODIS data for mapping wildlife habitat distribution. Remote Sensing of Environment, 112(5): 2160-2169. doi: 10.1016/j.rse.2007.09.012

Wang Song, 1998a. China Red Data Book of Endangered-
Animals. Beijing: Science Press, 1-95. (in Chinese)

Wang Song, 1998b. China Red Data Book of Endangered-Birds. Beijing: Science Press, 1-95. (in Chinese)

Warman L D, Forsyth D M, Sinclair A R E et al., 2004. Species distributions, surrogacy, and important conservation regions in Canada. Ecology Letters, 7(5): 374-379. doi: 10.1111/j.14610248.2004.00590.x

Wei Fuwen, Feng Zuojian, Wang Zuwang, 1999. Habitat selection by giant pandas and red pandas in Xiangling Mountains. Acta Zoologica Sinica, 45(1): 57-63. (in Chinese)

Williams P, Faith D, Manne L et al., 2006. Complementarity analysis: Mapping the performance of surrogates for biodiversity. Biological Conservation, 128(2): 253-264. doi: 10.1016/ j.biocon.2005.09.047

Xu W, Ouyang Z, Viña A et al., 2006. Designing a conservation plan for protecting the habitat for giant pandas in the Qionglai Mountain range, China. Diversity and Distributions, 12(5): 610-619. doi: 10.1111/j.1366-9516.2006.00236

Zeng Zhigao, Zhong Wenqin, Song Yanling et al., 2003. Present status of studies on eco-biology of Takin. Acta Theriologica Sinica, 23(2): 161-167. (in Chinese)

Zhou Youbin, Zhang Jinshuo, Suo Jianzhong et al., 2005. Capricornis sumatraensis. Chinese Journal of Zoology, 40(5): 84. (in Chinese) 